\title{
Fourier Transform Raman Studies of Methyl Red Adsorbed on $\gamma$-Alumina and Silica-Alumina
}

\author{
Sun-Kyung Park, Choongkeun Lee, Kỵung-Chul Min, and Nam-Soo Lee* \\ Department of Chemistry, Chunghuk National Chmersin, Cheongin $361-763$, Korea \\ Recened.August + , 2004
}

\begin{abstract}
Fourier transform Raman spectra of methyl red adsorbed on untreated and pretreated $\gamma$-alumina and silicaalumina calcined at $900^{\circ} \mathrm{C}$ under $1 \mathrm{~atm}$ steam flowing were recorded. Spectral analysis shows that the active species adsorbed on $\gamma$-alumina was to be deprotonated methyl red, and on silica-alunina to be di-protonated. This indicates that $\gamma$-alumina adapted in this work holds Brönsted basicity. and silica-alumina Brönsted acidity. Raman intensities of methyl red on pretreated $\gamma$-alumina are about three times stronger than on untreated $\gamma$ alumina. while spectral features are unchanged. For silica-alunina, spectral features show modified vibrational characteristics upon surface hydroxylations generated from pretreatment. Consequently, the acidity loss for silica-alumina and the basicity gain for $\gamma$-alumina were observed by increasing the surface hydroxyl groups on the catalysts through pretreatment of the steam calcination.
\end{abstract}

Key Words : Raman. Methyl red, Calcination, $\gamma$-Alumina, Silica-alumina

\section{Introduction}

The structure of azo dy'es has attracted considerable attentions recently due to their wide applicability in the light-induced photoisomerization process. and their potential usage for the reversible optical data storage. ${ }^{.}$Derivatives of 4-amino-trans-azobenzene are an important class of dyes for both natural and sy'nthetic fibres. They are also widely used as acid-base indicators and as spectrophotometric probes in chemistry: Such dyes undergo a color change on protonation. due to changes in their molecular and electronic structure. Methyl Red (MR) is a weakly basic azo dye with $\mathrm{p} K_{\mathrm{in}}=4.8$. and has been employed as a useful $\mathrm{p} H$ indicator in the range 4.4-6.0. in which it changes color from yellow in basic or neutral solution to red in acidic solution. ${ }^{2}$ The chemical structure of MR is shown in Figure 1. MR may be a good probe for reference molecule of acid-base study because the spectral features of neutral protonated. di-protonated and deprotonated MR are distinct from one another in the vibrational spectra. and further they have been well studied in the Raman spectroscopy. especially in resonance Raman spcetroscopy: so far. Resonance Raman (RR) studies of azobenzene and azonaphthalene derivatives have been reported and the key features of their spectra are well understood. The RR effect occurs when laser excitation is in close proximity to an intense electronic absorption band in which case there may be a $10^{3} 10^{4}$ fold enhancement of the normal Raman scattering signal. ${ }^{3}$ Usually. the enhancement factors of Raman band intensities in the resonance Raman scattering are quite selective to the modes and dependent on the electronic structure of molecules. However advantages of using an excitation wavelength departed from electronic absorption bands. such as $1064 \mathrm{~nm}$ laser. are well under-

\footnotetext{
"Corresponding Author. Phone: +82-43-261-2290; e-mail: nslee: chungbuk.ac.kr
}

stood. Employing such excitation wavelength, one could expect to obtain the vibrational characteristics of the sample from nearly normal Raman scattering. RR spectra give richer information for assignments because they have symmetry information of normal modes and afford classifying a number of normal modes into different symmetry blocks.

The oxides of aluminum and silicon are catalytically important materials that have been investigated extensively in order to determine the nature of their adsorption behaviors. Investigations have been concentrated on the several<smiles>CCN(C)c1ccc(N=Nc2ccccc2C(=O)O)cc1</smiles><smiles>CN(C)c1ccc(N=[NH+]c2ccccc2C(=O)O)cc1</smiles>

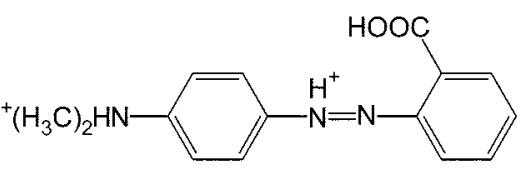

Figure 1. Chemical structures of MR species (from top: MRA, $\mathrm{MR}, \mathrm{MRH}$ and $\mathrm{MRHH}$ ) 
points. e.g. the geometry of sites (e.g. octahedral and tetrahedral environments of the highly defective spinel structures of aluminas), the type of bonding between substrate and adsorbate (e.g. physical adsorption whether of nonspecific nature due to dispersion forces or specific due to hydrogen bonding with surface hydroxyls). and the molecular dynamics of the adsorbed species (e.g. molecular diffusion and chemical exchange. which are important. for example. in cracking reactions). ${ }^{4}$ Aluminum oxide is an important teclunological material widely used in catalytic process. In particular. $\gamma-\mathrm{Al}_{2} \mathrm{O}_{3}$ is employed as a catalyst and a supporting material because of its acid-base properties. and its mechanical and high-temperature resistance. Surface properties of $\gamma-\mathrm{Al}_{2} \mathrm{O}_{3}$ have been the object of many experimental works using different probe molecules. Water adsorption has received special attentions since the basicity of this solid is generally related to the presence of surface hydroxyl groups. Under atmospheric conditions. the surfaces adsorb water both molecularly and dissociatively giving rise to surface hydroxyls that persist even at temperatures higher than $1000{ }^{\circ} \mathrm{C}$. The catalytic properties of amorphous silicaalumina catalysts are usually correlated with the Brönsted acidity that is located on the Al-OH-Si bridging bonds. Structural characteristics and reactivity properties of $\mathrm{Al}_{2} \mathrm{O}_{3} /$ $\mathrm{SiO}_{2}$ have been studied. Silica deposited on alumina is known to generate Brönsted acidity. Recently these metal oxides have been revisited and investigated to improve the catalytic selectivity and kinetics for a specific reaction in the envirommental chemistry ${ }^{7}$ and in the nano-particle chemistry.

In this study, we investigate Raman spectra of MR adsorbed on $\gamma$-alumina holding basicity and on silicaalumina holding acidity to elucidate active species on the catalyst surface and the steam calcination effects. Raman spectra of neutral mono-protonated di-protonated. and deprotonated species of MR were also obtained to compare with the spectra from the MR adsorbed on the solids. It is well recognized that $\gamma$-alumina and silica-alumina can display both acidity and basicity depending on pretreatment. Their acidic and/or basic sites may be classified as Lewis and/or Brönsted types. Steam calcinations of $\gamma$-alumina and silica-alumina were employed to investigate the acid-base types through the surface modification. By way of enforcing the hydroxyl groups on the surface of catalysts. it will be shown that the steam calcined silica-alumina decreased in the acidity strength, and the steam calcined $\gamma$-alumina increased in the basicity strength, and that $\gamma$-alumina adapted in this study has mainly Brönsted basic sites rather than Lewis types. while silica-alumina has mainly Brönsted acidic sites.

\section{Experimental Section}

MR was recrystallized from methanol and dried in vacuum. Toluene was dried over calcium chloride and distilled at atmospheric pressure. The protonated MR and deprotonated MR were prepared by mixing an equal or double molarity of $\mathrm{HCl}$ solution and an excess of $\mathrm{NaOH}$ solution. respectively.
Then dried in vacuum at room temperature. The $y$-alumina was purchased of the 0.05 micron from Baikowski International Corporation (Charlotte. North Carolina. USA). The silica-alumina was purchased of silica-alumina catalyst support from Aldrich Chemical Company. Two sets of samples were prepared containing untreated catalyst and pretreated catalyst calcined for 5 hours where the temperature was controlled at $900^{\circ} \mathrm{C}$ under water-steam flow in the atmospheric pressure. MR solution of $150 \mu \mathrm{M}$ in toluene was prepared. MR solution of $25 \mathrm{~mL}$ was added to each 50 $\mathrm{m} g$ sample of $\gamma$-alumina and silica-alumina. and then mixtures were allowed to equilibrate for 24 hours. The supernatant solution of each sample was decanted. and then the samples were dried in vacuum at room temperature

Bruker FRA106 Fourier transform spectrometer was applied in air purge mode to obtain Raman spectrum. It was equipped with $1064 \mathrm{~nm} \mathrm{cw} \mathrm{Nd}: Y A G$ laser, a calcium fluoride beam splitter and liquid nitrogen cooled Ge detector for Raman scattering. The laser power was about 0.1 watt at sample. The spectral resolution was set to $4 \mathrm{~cm}^{-1}$ and 100 times accumulated for each run. A sample powder was contained for irradiation with tight packing in ordinary melting point capillary tube (Drummond Scientific Co.).

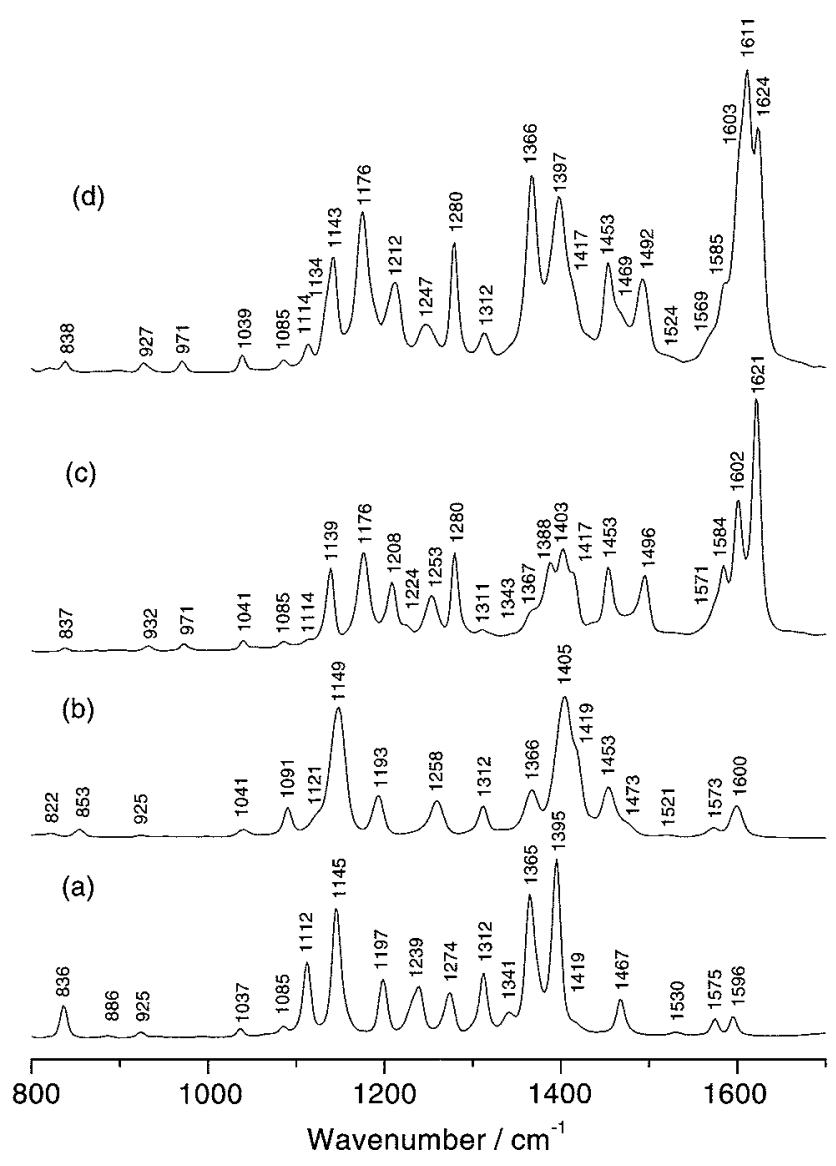

Figure 2. FT-Raman Spectra of Methyl Red (a), deprotonated Methyl Red (b), mono-protonated Methyl Red (c), and diprotonated Methyl Red (d). Excitation: $1064 \mathrm{~nm}$ Nd:YAG cw Laser, $4 \mathrm{~cm}^{-1}$ resolution, 100 Scans coadded for each. All samples are in powder forms dried in vacuum. 


\section{Results and Discussion}

Fourier transform Raman spectra in the mid-range of neutral (sy'mbol: MR). deprotonated (symbol: MRA), monoprotonated (symbol: MRH), and di-protonated (symbol: $\mathrm{MRHH}$ ) species of MR in the powder state are shown in Figure 2 and the band wavenumbers and their tentative assignments are given in Table 1. Table 2 and Table 3. respectively: These spectra are very similar to the resonance Raman spectra reported previously using $457.9 \mathrm{~nm}$ or 514.5 num excitation except Raman intensity features. ${ }^{\text {y. }} 10.11$ The spectrum of MR. Figure 2(a). shows a strong characteristic

Table 1. FT-Raman and resonance Rannan bands and assignnnents for Methyl Red

\begin{tabular}{|c|c|c|c|}
\hline \multirow{2}{*}{$\begin{array}{l}\text { FT Ramant } \\
\text { in Solid }\end{array}$} & \multicolumn{2}{|c|}{ Resonance Raman } & \multirow{2}{*}{ Assignments } \\
\hline & in $\mathrm{CH}_{2} \mathrm{Cl}_{2}{ }^{4}$ & in Methanol ${ }^{b}$ & \\
\hline 836 & 836 & 836 & $\delta_{p}$ (Ring-C) \\
\hline 886 & & & $\delta_{\mathrm{r}}(\mathrm{Ring}-\mathrm{H})$ \\
\hline 925 & 923 & 922 & $v(\mathrm{CNC})$ \\
\hline 1037 & & 1040 & $v$ (Ring Breathing) \\
\hline 1085 & & 1086 & $\delta\left(\mathrm{CH}_{3}\right.$ Rocking $)$ \\
\hline 1112 & 1115 & 1118 & $\delta_{p}($ Ring $-H)$ \\
\hline 1145 & 1150 & 1148 & $v(\mathrm{C}-\mathrm{N}=), \delta_{\mathrm{p}}(\mathrm{Ring}-\mathrm{H})$ \\
\hline 1197 & 1197 & 1198 & $v(=\mathrm{N}-\mathrm{C}), \delta_{\mathrm{p}}(\mathrm{R}$ (n) $\mathrm{g}-\mathrm{C})$ \\
\hline 1239 & 1240 & 1246 & $\delta_{p}($ Ring-H $)$ \\
\hline 1274 & 1280 & 1282 & $\delta_{p}(\mathrm{Ring}-\mathrm{H})$ \\
\hline 1312 & 1313 & 1314 & $v$ (amine $\mathrm{N}-\mathrm{C}$ ) \\
\hline 1341 & & & $\delta(\mathrm{C}-\mathrm{O}-\mathrm{H})$ \\
\hline 1365 & 1368 & 1368 & $v($ Ring-C $)$ \\
\hline 1395 & 1401 & 1402 & $v(\mathrm{~N}=\mathrm{N})$ \\
\hline 1419 & & & $\delta_{3}\left(\mathrm{CH}_{3}\right)$ \\
\hline 1467 & 1472 & 1460 & $v($ Ring-C $)$ \\
\hline 1530 & & & $v(\operatorname{Rin} g-C)$ \\
\hline 1575 & 1577 & 1576 & $v($ Ring-C $)$ \\
\hline 1596 & 1602 & 1603 & $v(\operatorname{Rin} g-C)$ \\
\hline
\end{tabular}

"from reference 11. "from reference 2

Table 2. FT-Raman and resonance Raman bands and assignments for Methyl Red Anion

\begin{tabular}{|c|c|c|}
\hline $\begin{array}{l}\text { FT Raman } \\
\text { in Solid }\end{array}$ & $\begin{array}{l}\text { Resonance Raman } \\
\text { in } \mathrm{KOH} \text { Solution }{ }^{\mathrm{a}}\end{array}$ & Assignunents \\
\hline 822 & & $\delta_{p}$ (Ring-C) \\
\hline 853 & & $\delta_{\mathrm{sp}}($ Ring-H $)$ \\
\hline 925 & 924 & $\delta(\mathrm{CNC})$ \\
\hline 1041 & & $v$ (Ring Breathing) \\
\hline 1091 & 1090 & $\delta\left(\mathrm{CH}_{3}\right.$ Rocking $)$ \\
\hline 1121 & & $\delta_{p}($ Ring-H) \\
\hline 1149 & 1150 & $v(\mathrm{C}-\mathrm{N}=), \delta_{p}(\mathrm{Ring}-\mathrm{H})$ \\
\hline 1193 & 1196 & $v(=\mathrm{N}-\mathrm{C})$ \\
\hline 1258 & 1266 & $\nu(=\mathrm{N}-\mathrm{C}), \delta_{\mathrm{as}}(\mathrm{CNC})$ \\
\hline 1312 & 1316 & $v($ amine $\mathrm{N}-\mathrm{C}$ ) \\
\hline 1366 & 1372 & $v($ Ring-C) \\
\hline 1405 & 1410 & $v(\mathrm{~N}=\mathrm{N})$ \\
\hline 1419 & 1420 & $\delta\left(\mathrm{CH}_{3}\right)$ \\
\hline 1453 & 1456 & $v($ Ring-C $)$ \\
\hline 1473 & 1474 & $v(\operatorname{Ring}-\mathrm{C})$ \\
\hline 1521 & & $v(\operatorname{Rin} g-C)$ \\
\hline 1573 & 1580 & $v($ Ring-C) \\
\hline 1600 & 1602 & $v($ Ring-C $)$ \\
\hline
\end{tabular}

"from reference II
Table 3. Resonance Raman and FT-Raman bands and assignments for protonated $\mathrm{MR}$ derivatives, $\mathrm{MRH}$ and $\mathrm{MRHH}$

\begin{tabular}{|c|c|c|c|}
\hline $\begin{array}{c}\text { Resonance Raman } \\
\text { of } \mathrm{MRH} \\
\text { in } \mathrm{H}_{2} \mathrm{O}\end{array}$ & $\begin{array}{l}\text { FT Raman } \\
\text { of MRH } \\
\text { in Solid }\end{array}$ & $\begin{array}{l}\text { FT Raman } \\
\text { of MRHH } \\
\text { in Solid }\end{array}$ & Assignments \\
\hline 840 & 837 & 838 & $\delta_{\mathrm{p}}$ (Ring-C) \\
\hline 926 & 932 & 927 & $d(\mathrm{C}-\mathrm{N}-\mathrm{C})$ \\
\hline \multirow[t]{2}{*}{972} & 971 & 971 & $\delta_{p}(\operatorname{Ring}-C)$ \\
\hline & 1041 & 1039 & $v$ (Ring Breathing) \\
\hline \multirow{2}{*}{1084} & 1085 & 1085 & $\delta\left(\mathrm{CH}_{3}\right.$ Rocking $)$ \\
\hline & 1114 & $\begin{array}{c}1114 \\
1134(\mathrm{sh})\end{array}$ & $\hat{d}_{\mathrm{N}}$ (Ring-H) \\
\hline $11+4$ & 1139 & 1143 & $\delta_{\mathrm{r}}($ Ring-H $)$ \\
\hline 1180 & 1176 & 1176 & $\delta_{p}$ (Ring-H) \\
\hline 1192 & 1208 & 1212 & $\hat{d}_{p}$ (Ring-H) \\
\hline 1220 & 1224 & & \\
\hline 1250 & 1253 & 1247 & $v(\mathrm{~N}=\mathrm{N}), v(=\mathrm{N}-\mathrm{C})$ \\
\hline \multirow[t]{3}{*}{1284} & 1280 & 1280 & $v(=\mathrm{N}-\mathrm{C}), v(\mathrm{~N}=\mathrm{N})$ \\
\hline & 1311 & 1312 & $v$ (amine $\mathrm{N}-\mathrm{C}$ ) \\
\hline & 1343 & (vw) & $\delta(\mathrm{C}-\mathrm{O}-\mathrm{H})$ \\
\hline 1366 & 1367 & 1366 & $v(\operatorname{Ring}-\mathrm{C})$ \\
\hline 1376 & 1388 & & $v(\operatorname{Rin} g-C)$ \\
\hline \multirow{2}{*}{1406} & 1403 & 1397 & $v(\mathrm{C}-\mathrm{N}=)$ \\
\hline & 1417 & $1+17$ & $\delta\left(\mathrm{CH}_{3}\right)$ \\
\hline 1456 & 1453 & 1453 & $v(\operatorname{Ring}-C)$ \\
\hline \multirow[t]{2}{*}{1496} & 1496 & $\begin{array}{l}1492 \\
1524\end{array}$ & $v(\operatorname{Ring}-C)$ \\
\hline & 1571 & 1569 & $v(\operatorname{Ring}-C)$ \\
\hline 1588 & 1584 & 1585 & $v(\operatorname{Ring}-C)$ \\
\hline \multirow[t]{2}{*}{1606} & 1602 & 1603 & $v(\operatorname{Ring}-\mathrm{C})$ \\
\hline & & 1611 & $v(\operatorname{Ring}-C)$ \\
\hline 1620 & 1621 & 1624 & $v(\operatorname{Ring}-\mathrm{C})$ \\
\hline
\end{tabular}

"from reference II

$\mathrm{N}=\mathrm{N}$ stretching band at $1395 \mathrm{~cm}^{-1}$ which is down-shifted 6 $\mathrm{cm}^{-1}$ to the resonance Raman band in solution previously reported. ${ }^{11}$ A weak band at $1419 \mathrm{~cm}^{-1}$ is assigned to the $\mathrm{CH}_{3}$ symmetric deformation. Five bands at 1365. 1467. 1530. 1575 and $1596 \mathrm{~cm}^{-1}$ are the ring stretching modes attributed to two substituted benzene rings in MR. On comparison with the spectra of MR. the spectrum of MRA. Figure 2(b). shows a strong characteristic $\mathrm{N}=\mathrm{N}$ stretching band at 1405 $\mathrm{cm}^{-1}$ which is up-shifted $10 \mathrm{~cm}^{-1}$. The intensity of 1366 $\mathrm{cm}^{-1}$ band attributed to the stretching of ring. $v$ (Ring-C) is decreased. It appears that the localized ring conjugation and $\mathrm{N}=\mathrm{N}$ stretching in MRA species are rather stronger than neutral MR. The spectra of MRH and MRHH. Figure 2(c) and Figure 2(d). are markedly different from those of the MR and MRA.

Very strong bands at $1621 \mathrm{~cm}^{-1}$ for MRH and 1611 and $1624 \mathrm{~cm}^{-1}$ for MRHH are assigned to the stretching of ring vibration. $v$ (Ring-C) confirming the existence of quinonoid character of the ring system in the protonated species. The intensities of the peaks $\left(1450 \mathrm{~cm}^{-1} \sim 1600 \mathrm{~cm}^{-1}\right)$ attributed to the ring stretching vibration (Wilson modes 8 a. $8 \mathrm{~b} .19 \mathrm{a}$ and 19b) are strong in protonated species comparing with those of the MR or MRA. The peak attributed to the ring breathing mode is present at $1041 \mathrm{~cm}^{-1}$ in the spectra of protonated and anionic species. which are $4 \mathrm{~cm}^{-1}$ up-shifted to $1037 \mathrm{~cm}^{-1}$ in MR. The bands at 1253 and $1280 \mathrm{~cm}^{-1}$ for MRH and 1247 and $1280 \mathrm{~cm}^{-1}$ for MRHH assigned to 


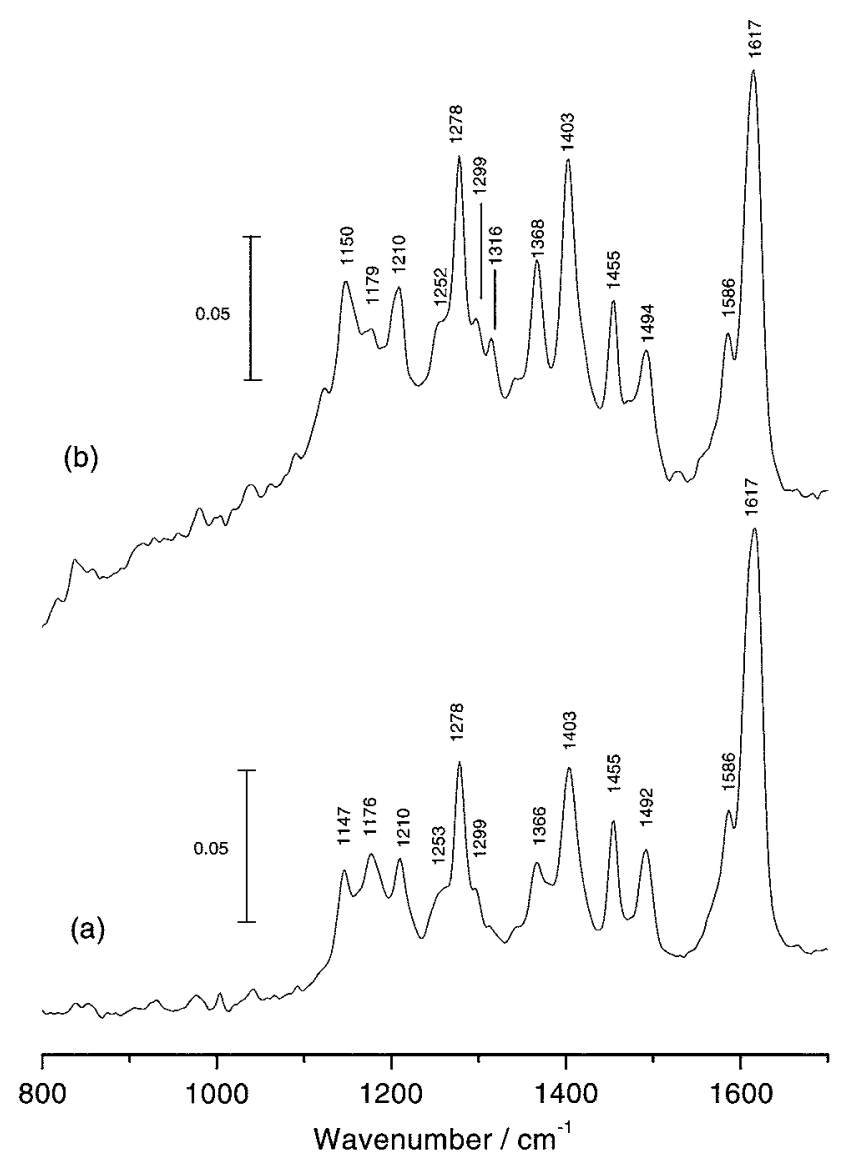

Figure 3. FT-Raman Spectra of Methyl Red Adsorbed on untreated silica-alumina (a) and on pretreated silica-alumina (b). Experinental conditions are the same as in Figure 2.

stretchings of both $v(\mathrm{~N}=\mathrm{N})$ and $v(=\mathrm{N}-\mathrm{C})$ have shown that MR species is protonated to nitrogen atom of azo group. The double bond character between $\mathrm{N}$ and $\mathrm{N}$ is weaker and has some degrees of the single bond characteristics. Though the spectra of MRH and MRHH are looking nearly the same. MRHH has rather strong azo-dye character than MRH..$^{10.11 .12}$ This feature could be seen from the recovered strong bands at 1366 and $1397 \mathrm{~cm}^{-1}$ in Figure 2(d) which were observed strong in neutral MR. Figure l(a). but not strong enough either in MRH. Figure 2(c) or MRA. Figure 2(b). These recovered features due to di-protonation in less $1400 \mathrm{~cm}^{-1}$ range for MRHH may show ideas of any conformational changes (cis-to-trans, or vice versa) induced by adsorption of MR on the colloid surface ${ }^{13}$ or any structural changes (quinonoid-to-azo form. or vice versa) due to the inclusion of azonium group into cyclodextrin."

The spectra of MR species adsorbed on untreated silicaalumina are shown in Figure 3(a) and the band wavenumbers and tentative assignments are given in Table 4 . The spectra of MR species adsorbed on silica-alumina quite resemble those obtained for protonated MR. Figure 2(c). Very strong band at $1617 \mathrm{~cm}^{-1}$ is assigned to the $v$ (Ring-C) vibration of the quinonoid structure adopted by protonated MR. The peaks in the region $1450 \mathrm{~cm}^{-1}$ to $1600 \mathrm{~cm}^{-1}$ are attributed to the ring stretching vibration (Wilson modes 8a, 8b. 19a and
Table 4. FT-Raman bands and assignments for MR species adsorbed on silica-alumina and $\psi$-alumina

\begin{tabular}{|c|c|c|c|c|}
\hline \multicolumn{2}{|c|}{ MR/Silica-Alumina } & \multicolumn{2}{|c|}{ MR/y-Alumina } & \multirow{2}{*}{ Assignments } \\
\hline Untreated & Calcined & \multicolumn{2}{|c|}{$\overline{\text { Untreated Calcined }}$} & \\
\hline \multirow[t]{2}{*}{$(974)^{a}$} & $(970)^{6}$ & \multirow{4}{*}{$\begin{array}{l}1093 \\
1150\end{array}$} & \multirow{4}{*}{$\begin{array}{l}1094 \\
1149\end{array}$} & $\delta_{j p}(\operatorname{Rin} g-C)$ \\
\hline & & & & $\delta\left(\mathrm{CH}_{3}\right.$ Rocking $)$ \\
\hline $1147(1145)$ & $1150(1146)$ & & & $\delta_{\mathrm{jp}}(\mathrm{Ring}-\mathrm{H})$ \\
\hline $1176(1172)$ & $1179(1172)$ & & & $\delta_{\mathrm{sp}}(\mathrm{Ring}-\mathrm{H})$ \\
\hline & & \multirow[t]{3}{*}{1193} & \multirow[t]{3}{*}{1195} & $v(=\mathrm{N}-\mathrm{C})$ \\
\hline $1210(1218)$ & $1210(1216)$ & & & $\delta_{\mathrm{ip}}(\mathrm{Ring}-\mathrm{H})$ \\
\hline $1253(1246)$ & $1252(1247)$ & & & $v(\mathrm{~N}=\mathrm{N}), v(=\mathrm{N}-\mathrm{C})$ \\
\hline $1278(1274)$ & $1278(1275)$ & \multirow[t]{2}{*}{1262} & \multirow[t]{2}{*}{1264} & $v(=\mathrm{N}-\mathrm{C}), \delta_{a s}(\mathrm{CNC})$ \\
\hline $1299(1294)$ & $1299(1295)$ & & & \\
\hline weak ( & 13160 & 1314 & 1314 & $v$ (amine $\mathrm{N}-\mathrm{C}$ ) \\
\hline $1366(1364)$ & $1368(1363)$ & 1368 & 1368 & $v(\operatorname{Ring}-\mathrm{C})$ \\
\hline \multirow[t]{3}{*}{$1403(1400)$} & $1403(1399)$ & & & $\delta\left(C^{\prime}-N^{2}=\right)$ \\
\hline & & 1411 & 1411 & $v(\mathrm{~N}=\mathrm{N})$ \\
\hline & & 1422 & $1+21$ & $\delta_{s}\left(\mathrm{CH}_{3}\right)$ \\
\hline $1455(1452)$ & $1455(1452)$ & 1459 & 1459 & $v(\operatorname{Ring}-\mathrm{C})$ \\
\hline $1492(1490)$ & $1494(1489)$ & & & $v(\operatorname{Rin} g-C)$ \\
\hline $1586(1576)$ & $1586(1582)$ & \multirow{3}{*}{1602} & \multirow{3}{*}{1602} & $v(\operatorname{Rirlg}-\mathrm{C})$ \\
\hline & 16 & & & $v$ (Ring-C) \\
\hline $101 / 4$ & 1017 & & & $v(\mathrm{~K} m$ \\
\hline
\end{tabular}

The ralues in the parentheses are resonance Raman bands from reference 14

19b). Like protonation of MR. the substrate holds surface sites which can donate protons to adsorbates adsorbed on the silica-alumina surfaces. resulting in protonation of adsorbed MR species. Consequently, the examination of the spectra reveals that the silica-alumina surfaces function as the Brönsted acidic sites. The spectra of MR adsorbed on calcined silica-alumina are shown in Figure 3(b) and the band wavenumbers and assignments are given in Table 4 . The spectrum Figure 3(b) represents the properties of Brönsted acid and Brönsted base. On comparison with the spectra of MR adsorbed on untreated silica-alumina, major differences between them are weaker intensity of a band at $1179 \mathrm{~cm}^{-1}$ and stronger intensities of bands at $1316 \mathrm{~cm}^{-1}$ and $1368 \mathrm{~cm}^{-1}$. These features are also observed in Figure 2(b) and Figure 2(c). For MRA shown in Figure 2(b). we can deduce strong delocalization through azo $\mathrm{N}=\mathrm{N}$ bond conjugated to two ring systems. but for MRH in Figure 2(c) a lot weaker $\mathrm{N}=\mathrm{N}$ bonding character and quinonoid structural characters in the ring systems. Characteristic features for $\mathrm{MRH}$ in resonance Raman or surface enhanced Raman were known to be strong two bands at 1176 and 1620 $\mathrm{cm}^{-1}$. which was also verified in Figure 2(c). The other notable difference in Figure 3(b), rather stronger intensity of a band at $1368 \mathrm{~cm}^{-1}$ could mean relatively higher degrees of azo-dye character in the molecular system. It is evident from these spectra that the proportion of Brönsted acid site on calcined silica-alumina is smaller than on the untreated silica-alumina. But Brönsted base sites are partly formed on the calcined silica-alumina surfaces due to adsorption of hỵdroxyl ions during steam calcination. instead.

In different from the spectra of MR species adsorbed on silica-alumina. the spectra of MR species adsorbed on $\gamma$ 


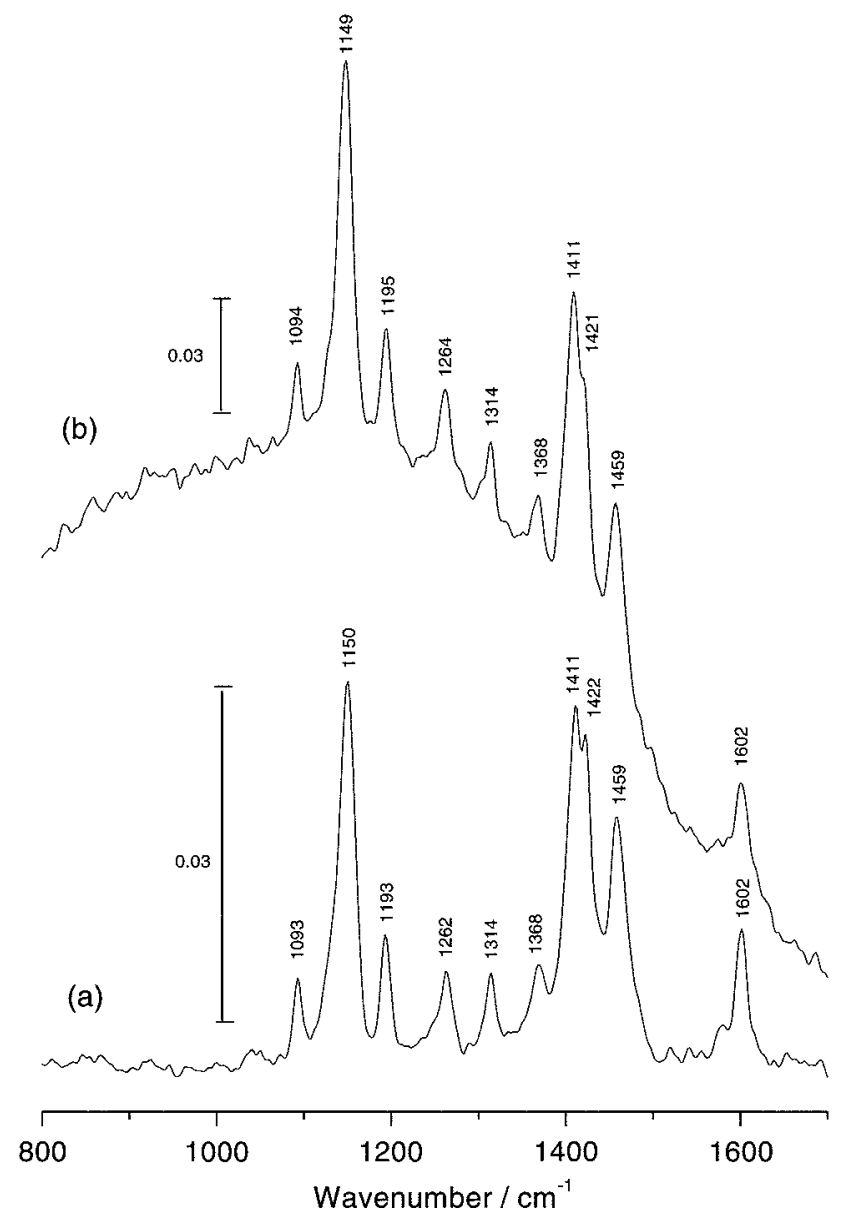

Figure 4. FT-Raman Spectra of Methyl Red Adsorbed on untreated ralumina (a) and on pretreated Yalumina (b). Esperinental conditions are the same as in Figure 2.

alumina closely resemble the spectra obtained for deprotonated MR. The spectra of MR species adsorbed on untreated Falumina are shown in Figure 4(a) and the band wavenumbers and tentative assignments ${ }^{14}$ are given in Table 4 . For MR species adsorbed on $\gamma$-alumina the strong bands are at $1150 \mathrm{~cm}^{-1}$ attributed to $\delta_{\mathrm{p}}($ Ring- $\mathrm{H})$ and $v(\mathrm{C}-\mathrm{N}=)$, and $1411 \mathrm{~cm}^{-1}$ assigned to the $v(\mathrm{~N}=\mathrm{N})$ vibration. On comparison with the spectrum of MR. the spectra of MR species adsorbed on Yalumina have shown that the intensity of the band attributed to $v$ (Ring-C) is weaker and the intensity of the band attributed to $v(\mathrm{~N}=\mathrm{N})$ stronger. It appears that $\mathrm{MR}$ species adsorbed on $\gamma$ alumina is strongly conjugated further than in neutral MR. Usually alumina surfaces used at the majority of the catalytic reaction had been known to possess acidic sites. but in this adsorption study of MR it proves from spectral analysis that $\gamma$-alumina surfaces holds basic sites. Like deprotonation of MR. the sites deprotonate MR species adsorbed which could accept protons from adsorbates on $\gamma$ alumina surfaces. In this case $\gamma$ calumina surfaces play a role as Brönsted basic sites. The spectra of MR adsorbed on calcined \%alumina are shown in Figure 4(b) and the band wavenumbers and assignments are given in Table 4 . The spectral features of Figure 4(a) and Figure 4(b) are nearly the same except spectral intensity. The intensity of MR species adsorbed on calcined yalumina is much higher about three times than that of MR adsorbed on untreated $\gamma$ alumina. This observation can be explained as increased population of basic active sites in the calcined yalumina surfaces resulting from increased hỵdroxyl groups generated during stean calcination.

\section{Conclusions}

The active species adsorbed on $\gamma$ alumina was proved to be deprotonated methyl red. and on silica-alumina to be diprotonated methyl red. It is evident from the spectra analysis that hydroxyl groups are generated on the surfaces of oxides during steam calcination. Silica-alumina surface has Brönsted acidic site. and $\gamma$ alumina surface Brönsted basic site. Steam calcinations of $\gamma$ alumina and silica-alumina were employed to investigate the acid-base types through the surface modification. By way of enforcing the hydroxyl groups on the surface of catalysts. it is shown that the steam calcined silica-alumina decreased in the acidity strength. and the steam calcined $\gamma$ alumina increased in the basicity strength. and that $y$ kalumina adapted in this study has mainly Brönsted basic sites rather than Lewis types. while silicaalumina has mainly Brönsted acidic sites.

Acknowledgement. This work was supported by Chungbuk National University Grant in 2004. in part. Also, we acknowledge Brain Korea 2l Program of the Ministry of Education and Human Resources Development, Korea for the financial support.

\section{References}

1. (a) Biswas. N.: Unapathy. S. J. Phws Chent A 1997. 101. 5555. (b) Inoue. K.: Takeuchi. H.: Konaka. S. J. Phis. Chent. A 2001. 105. 6711. (c) Tsuji. T.: Takashima. H.: Takeuchi. H.: Egawa. T:: Konaka, S. J. Phus. Chem. A 2001. 105, 9347. (d) Park. H. S.: Oh. K. S.: Kim. K. S.: Chang. T; Spiegel. D. R. J. Ploys. Chem. B 1999, 103, 2355.

2. Bell. S.: Bisset. A.: Dines. T. T. J. Raman Spectrose. 1998. 29. 447.

3. Bisset. A.: Dines. T. T. J. Rantan Spectrose. 1995. 26.791.

4. Tanabe, K: Misono, M:; Ono. Y: Hattori. H. New Solid tcids and Bases: Elsevier: Amsterdam, 1989.

5. Sanz. J. F.: Rabaa, H.: Poveda, F. M.; Marquez. A. M.: Calzado. C. J. Inter. J. Ouanthm Chent 1998. 70.359.

6. Gao. X.: Wachs. I. E. J. Catal. 20M0. 192. 18.

7. Kidwai. M: Rastogi. S.: Saxena. S. Bull. Korem Chem. Soc. 2003. 24,1575 .

8. (a) Yoo, J. W. Lee, S. M: Kim. H. T: El-Sayed, M. A. Bull. Korean Chem Soc. 2004. 25. 843. (b) Choi, H. -W. Woo. H.-J.; Kim. J.-K.: Kim. G. -D.: Hong. W.: Ji. Y.-Y. Bull. Konew Chen. Soc. 2004. 25.535.

9. Yamamoto. H.: Maeda. Y: Kitano. H. J. Phus. Chent. B 1997. 101. 6855 .

10. Wang, K.: Li. Y.S. Tib. Spectrosc. 1997, 1H. 183.

11. Michl. M.: Vlckova, B; Mojzes, P. J. 1 Hol. Struct. 1999. 482,217

12. Michl. M.: Vlckova. B.: Mojzes. P. Iíb. Spectrosc. 1999. 19. 239.

13. Bachachashilli. A.: Katz. B.: Priel. Z.: Efrima. S. J. Phss. Chent. 1984. 88.6185.

14. Bisset. A.: Dines. T. J. J. Chem. Soc. Faraday Trans. 1997, 93(8). 1629. 